\title{
Implantable cardioverter defibrillators in sub-saharan africa center: Three case series and challenges in management
}

\author{
Edafe E Auchi ${ }^{1,2 *}$ and Dodiyi-Manuel Sotonye $\mathrm{T}^{2}$ \\ ${ }^{1}$ Department of Cardiology Unit, Bayelsa Specialist Hospital, Yenagoa, Bayelsa State, Nigeria \\ ${ }^{2}$ Department of Internal Medicine, University of Port Harcourt Teaching Hospital, Port Harcourt, Nigeria
}

\begin{abstract}
Implantable Cardioverter Defibrillators (ICDs) are valuable devices for prevention of primary or secondary cardiac arrest and sudden cardiac death. While the causes of sudden cardiac death and arrest exists throughout the world. These life saving devices to prevent sudden cardiac death are expensive in sub-Saharan Africa where the patient pay out of pocket. In this study, we discuss 3 ICDs case series and challenges in management.
\end{abstract}

\section{Introduction}

Implantable Cardioverter Defibrillators (ICDs) are vital in preventing sudden death in patients with known, sustained ventricular tachycardia or fibrillation [1]. Studies have shown ICDs to have a role in preventing cardiac arrest in high-risk patients who have not had, but are at risk for, life-threatening ventricular arrhythmias [2-4]. The implantations of ICDs are on the increase in the sub-Saharan Africa. The aim of this study was to discuss the 3-case series and challenges in the management of these patients in the region.

\section{Case 1}

He is a 69 -year-old man living with hypertension for 23 years. He developed ST-segment elevation Myocardial Infarction in March 2019 for which he was treated with a percutaneous coronary intervention (PCI) with drug eluding stent (Resolute Integrity, Zotarolimus, $3 \mathrm{~mm}$ by $18 \mathrm{~mm}$ ) to the proximal left descending coronary artery (Figure 1). He had ventricular tachycardia alternating with ventricular fibrillation by April 2019. This was aborted by chemical cardiovertion with Amiodarone and one shock from automated external defibrillator (AED) same day. Patient did not receive Implantable Cardioverter Defibrillator due to lack of finance to pay for the ICD. He was discharged home on telmisartan $80 \mathrm{mg}$ daily, Aspirin $75 \mathrm{mg}$ daily, clopidogrel 75 $\mathrm{mg}$ daily, atorvastatin $40 \mathrm{mg}$ nocte and Natrilix SR $1.5 \mathrm{mg}$ daily and oral Amiodarone $400 \mathrm{mg}$ daily.

He presented again to the emergency with dizziness and chest discomfort of 1-day duration in December 2019. The Emergency monitor and electrocardiogram showed ventricular tachycardia. This was aborted in the hospital with intravenous infusion of Amiodarone and one 150 joules shock from a defibrillator. Post cardiovertion, he was conscious, afebrile, anicteric, acyanosed. Pulse 130bpm, blood pressure 150/82 mmHg, heart sounds were S1 and S2. Chest examination showed normal vesicular sound, no crepitation. Other systemic examinations were essentially normal. Sodium was $137 \mathrm{mmol} / \mathrm{l}$, potassium $3.8 \mathrm{mmol} / \mathrm{l}$, urea $4.2 \mathrm{mmol} / \mathrm{l}$, creatinine $78 \mu \mathrm{mol} / \mathrm{l}$. We made assessment of PostMyocardial Infarction Ventricular arrhythmias (VT/VF). He was advice on ICD implantation, continue the oral Amiodarone at $400 \mathrm{mg}$
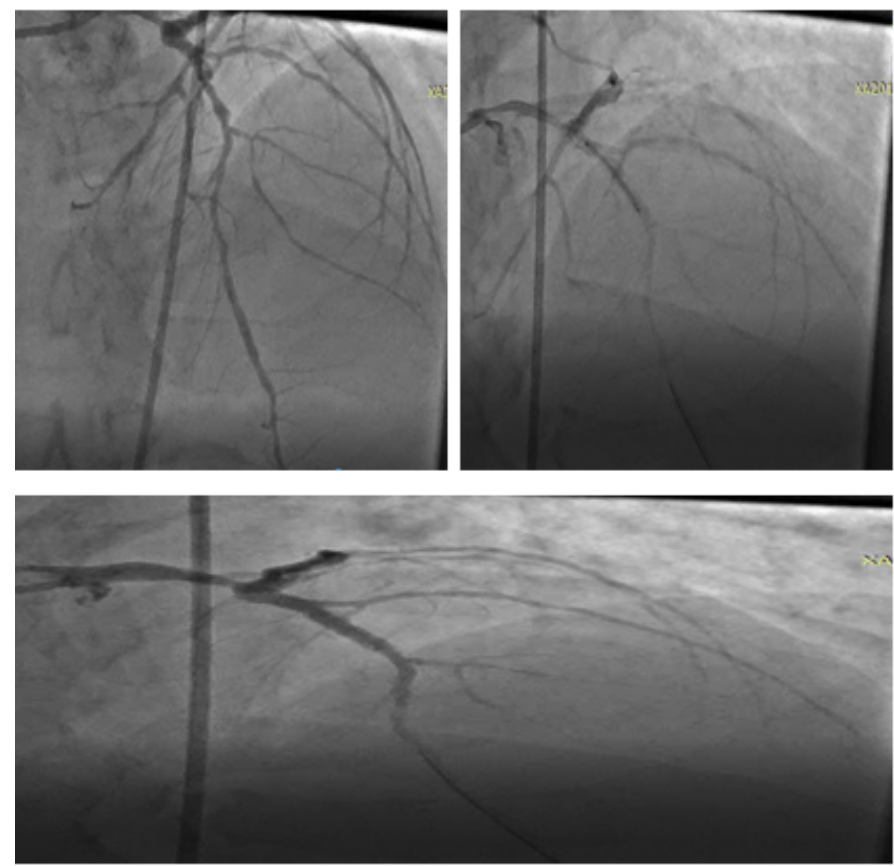

Figure 1. Coronary angiogram and stent. a. Coronary angiogram, LAD is $80-86 \%$. b. During coronary stenting. c. Post stenting

daily, Aspirin $75 \mathrm{mg}$ daily, clopidogrel $75 \mathrm{mg}$ daily, atorvastatin $40 \mathrm{mg}$ nocte, telmisartan $80 \mathrm{mg}$ daily, Nitrilix SR $1.5 \mathrm{mg}$ daily. Informed consent was taken for the procedure, part preparation was both upper chest clivicular region.

${ }^{\star}$ Correspondence to: Edafe Emmanuel Auchi, Department of Cardiology Unit, Bayelsa Specialist Hospital, Yenagoa, Nigeria, E-mail: dremmanueledafe@gmail.com

Key words: implantable cardioverter defibrillator, challenges in management, subsaharan africa

Received: February 20, 2020; Accepted: February 27, 2020; Published: March 09,2020 
Procedure: Strict adherence to sterile techniques was observed. The patient was prepared betadaine solution and sterile drapes. The pocket was created by horizontal incision $2 \mathrm{~cm}$ distal to the left clavicle. The dissection continued till the white fascia covering the Pectoalis major and bluntly extended till the size of the ICD pulse generator. The next step was to gain access through the subclavain vein with a needle and guidewire. The pill off shealth (9F) was inserted. The lead was advanced to the septum and fix on it (table 1 showed the device implant data and parameters) (Table 1). The lead was fixed to the pulse generator (Figure 2). The VF and VT functions were turn on. The anti-bradycardia function was programmed at $40 \mathrm{bpm}$. The pocket was closed, and the bill was agreed to be paid over a period of 6 month. He was discharge home on the third day post-procedure.

Follow up: He has been on follow up. He was advice to come for interrogation at 4-week post implant. He was also advice to come to hospital if there any symptom such as chest pain, dizziness or sound from the device. He had one episode of shock at 3 weeks and he presented, and the device was interrogated. There was episode of VF which the device responded by delivering two shocks. He was sent home same day after the interrogation.

\section{Case 2}

A 69-year-old Nigerian male with a medical history of hypertensive heart disease and type 2 Diabetes Mellitus of 10 years duration. He had coronary angiogram which normal coronaries with slow flow in September 2018 (Figure 3a). The right heart catheterization showed pulmonary hypertension with pulmonary capillary wedge pressure of

Table 1. Implant data parameter

\begin{tabular}{|c|c|}
\hline Parameter & RV lead/generator \\
\hline Manufacturer & Medtronic \\
\hline Device type & Protecta \\
\hline RV Lead Serial number & TDG660423V \\
\hline RV LEAD Model & 6947 \\
\hline R wave & 8.7 volts \\
\hline Impedance & 674 Ohms \\
\hline Threshold & 0.3 volts \\
\hline Pulse generator MODE & D354VRG \\
\hline Pulse generator Serial number & S/N: PSG616326S \\
\hline
\end{tabular}
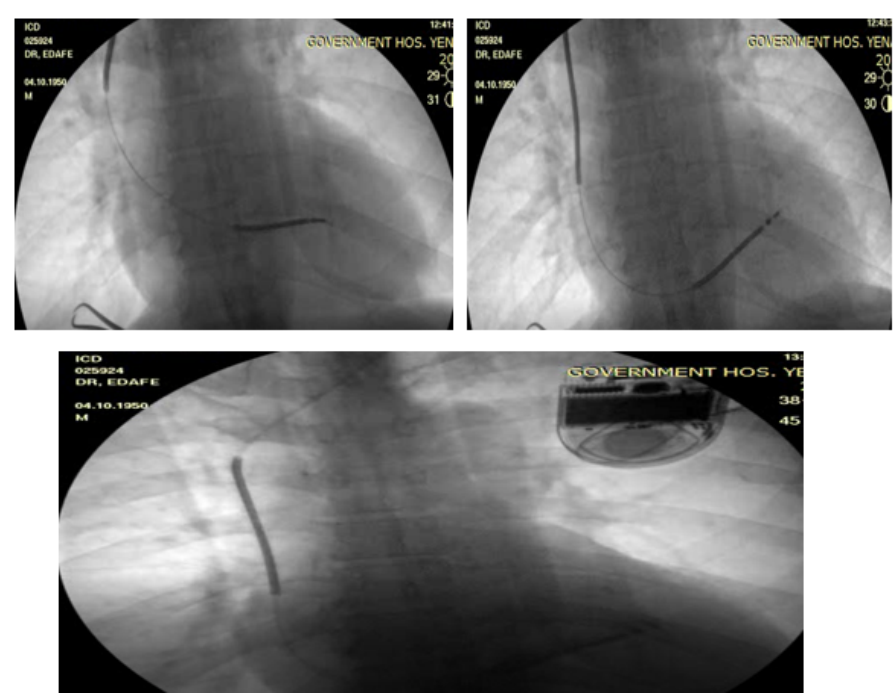

Figure 2. a, b and c showed the single chamber ICD. a. During lead position, b. Lead positioned to the septum, c. Final fluoroscopy after the implantation

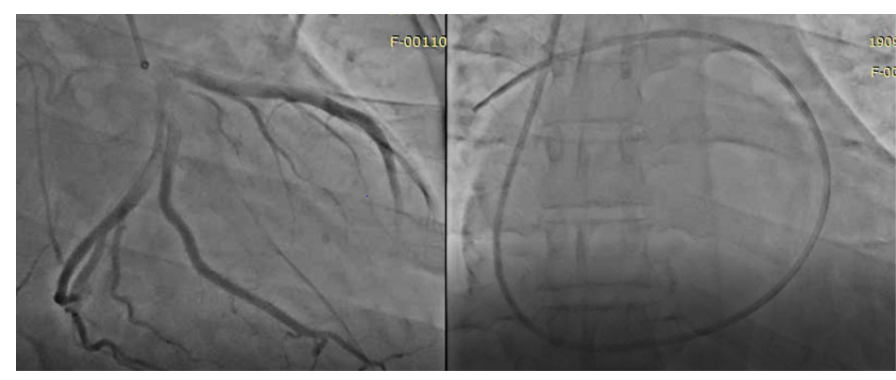

Figure 3. (a) Coronary angiogram showed normal coronaries with slow flow, (b). Right heart catheterization with Swan Gan catheter

$21 \mathrm{mmHg}$ (Figure $3 \mathrm{~b}$ ). He has been regular with his medications. He has sudden cardiac arrest in January 2019. He was resuscitated with Cardiopulmonary resuscitation and multiple shocks from defibrillator. He was advice on Implantable cardiac defibrillator ICD but decline due to inability to fund the procedure. He was on amiodarone $400 \mathrm{mg}$ daily. His echocardiography showed four chamber dilatations with reduced ejection fraction at $35 \%$ and grade 3 diastolic dysfunction. In July 2019, he had an had a ventricular tachycardia which he received appropriate electrical shocks from the automated external defibrillator (AED).

He presented again the emergency room of the Bayelsa Specialist Hospital, Yenagoa with complain of chest pain and dizziness of 6-day duration. There is associated history of syncope and pre-syncopal attack. He was fully conscious with Glasgow coma scale score of 15/15 (eye oponing 4, verbal response 5 and motor response 6). His heart rate was $126 \mathrm{bpm}$, blood pressure was $140 / 80 \mathrm{mmHg}$.

His ECG showed ventricular tachycardia (Figure 4). Laboratory investigations showed normal values for complete blood cell count, electrolytes, and cardiac enzymes. As for electrolytes, he had a potassium level of $4 \mathrm{mmol} / \mathrm{l}$ (normal: $3.6-5.0 \mathrm{mmol} / \mathrm{l}$ ), sodium of $136 \mathrm{mmol} / \mathrm{l}$ $(136-145 \mathrm{mmol} / \mathrm{l})$, urea $3.5 \mathrm{mmol} / \mathrm{l}$, creatinine $89 \mu \mathrm{mol} / \mathrm{l}$. We admitted he to the hospital with an assessment of heart failure with reduced ejection secondary to Dilated Cardiomyopathy and complicated with pulmonary hypertension and with Ventricular Tachycardia. We admitted him for to the intensive care unit. He was counseled for Single Chamber ICD. The medications included oral Amiodarone $400 \mathrm{mg}$ daily, oral furosemide $40 \mathrm{mg}$ twice daily, oral telmisartan $40 \mathrm{mg}$ daily, oral spironolactone $25 \mathrm{mg}$ daily, metoprolol XL $50 \mathrm{mg}$ daily.

Procedure: Strict adherence to sterile techniques was observed. The patient was prepared betadaine solution and sterile drapes. Tumescent anesthesia with $2 \%$ lidocaine, bupivacaine and normal saline in the ratio of 15:10:5 was mixed and given locally. The pocket was created by horizontal incision $2 \mathrm{~cm}$ distal to the left clavicle. The dissection continued till the white fascia covering the Pectoalis major and bluntly extended till the size of the ICD pulse generator. The next step was to gain access through the subclavain vein with a needle and guidewire. The pill off shealth (9F) was inserted. The lead was advanced to the RV apex and fix on it (table 2 showed the device implant data and parameters) (Table 2). The lead was fixed to the pulse generator (Figure 5). The VF and VT functions were turn on. The anti-bradycardia function was programmed at $40 \mathrm{bpm}$. The pocket was closed. The bill was agreed to be paid over a period of 12 month. He was discharge home on the third day post-procedure.

Follow up: He has been on follow up. He was advice to come for interrogation at 4 -week post implant. He was also advice to come to hospital if there any symptom such as chest pain, dizziness or sound from the device. He has been regular with his medications. 


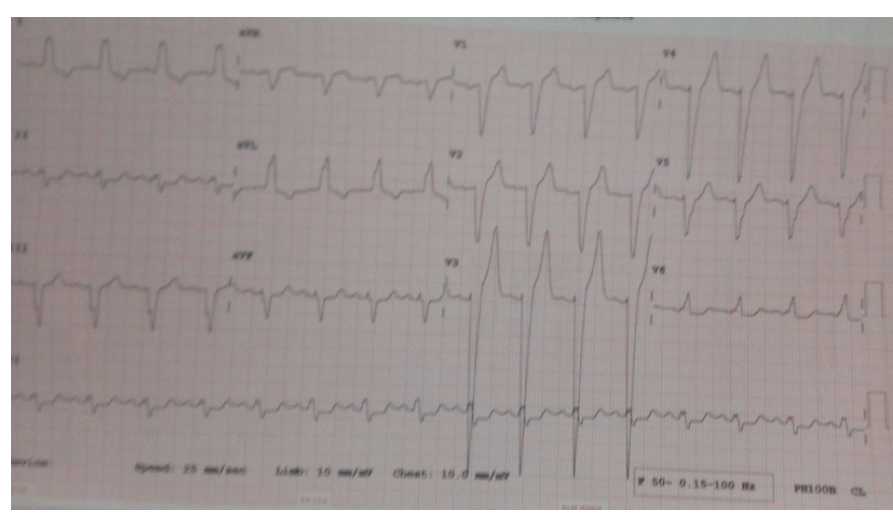

Figure 4. Monomorphic ventricular tachycardia
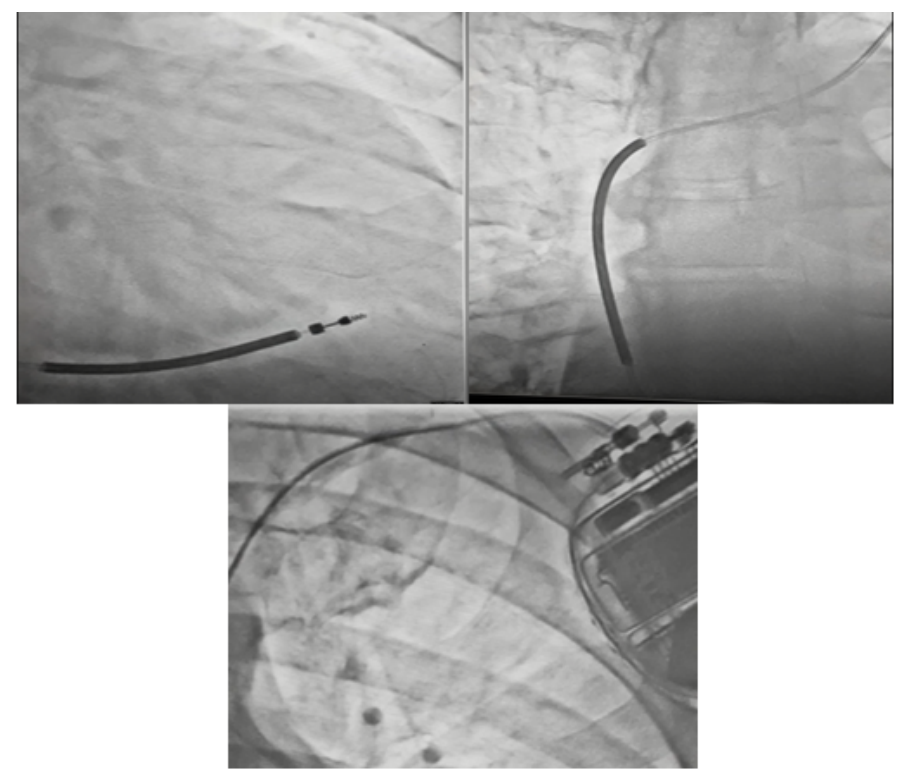

Figure 5. Single chamber ICD with the lead positioned at the RV apex

Table 2. Implant data parameter

\begin{tabular}{|c|c|}
\hline Parameter & RV lead/ generator \\
\hline Manufacturer & Medtronic \\
\hline Name & Protecta \\
\hline RV lead serial number & TDX5704623N \\
\hline RV lead mode & 7682 \\
\hline R wave & 15.6 volts \\
\hline Impedance & 702 ohms \\
\hline Threshold & 0.5 volts \\
\hline Pulse generator Mode & D334VRG \\
\hline Pulse generator serial number & PSX206433H \\
\hline
\end{tabular}

\section{Case 3}

Mrs. ADN is a 71-year-old female living with hypertensive and depression of 10 years duration with poor drug adherence. She has had two episodes of cardiac arrest in the past with Electrocardiography evidence of Ventricular Tachycardia alternating with Ventricular Fibrillation. These first and second episodes occurred in May 2017 and August 2019 respectively. She was informed about Implantable Cardioverter Defibrillator during the second events, but she declined due to inability to fund the procedure.
She again in December 2019 presented to the emergency unit with complaint of recurrent chest pain of 24 hours duration. Each episode lasting 10-20 minutes. Pain is in the precordial region, and nonradiating. Patient graded pain 6 on a scale of 1 to 10 . No history of vomiting, no abdominal distention and no lower limb weak. She did not use tobacco in any form. While she is having the pain, her son called me on the phone, and I instructed her to come to hospital Emergency room. The ECG done on arrival to the Emergency room while the pain was ongoing showed Ventricular Tachycardia (Figure 6).

Examination showed a conscious middle elderly woman, not in obvious distress, anicteric acyanosed and no pedal edema. Temperature $370 \mathrm{C}$, Respiratory rate $20 \mathrm{cpm}$, Pulse $120 \mathrm{bpm}$. Her blood pressure is $180 / 100 \mathrm{mmHg}$, Hear sounds S4, S1, S2. Nervous system examination showed no focal neurologic deficit. A working diagnosis of hypertensive Ischemic heart disease with recurrent Ventricular Tachycardia was made.

The patient was admitted to the Intensive Care Unit and reviewed by cardiology team. The sodium was $139 \mathrm{mmol} / \mathrm{l}$, Potassium was 3.6 mmo/l, chloride $109 \mathrm{mmol} / \mathrm{l}$, Urea $3.9 \mathrm{mmo} / \mathrm{l}$, Creatinine $78 \mu \mathrm{mol} / \mathrm{l}$, troponin I $1.9 \mathrm{ng} / \mathrm{ml}$ (normal is less thank than $0.5 \mathrm{ng} / \mathrm{ml}$ ).

Echocardiography: It showed concentric LVH with ejection fraction of $46 \%$ and grade 1 diastolic failure. The coronary angiogram showed multiple dilated and aneurysmal right and left coronaries (Figure 7). She was advice for Implantable Cardioverter Defibrillator.

Procedure: Strict adherence to sterile techniques was observed. The patient was prepared betadaine solution and sterile drapes. Tumescent anesthesia with 2\% lidocaine, bupivacaine and normal saline in the ratio of 15:10:5 was mixed and given locally. The pocket was created by horizontal incision $2 \mathrm{~cm}$ distal to the left clavicle. The dissection continued till the white fascia covering the Pectoalis major and bluntly extended till the size of the ICD pulse generator. The next step was to gain access through the subclavain vein with a needle and guidewire. The pill off shealth $(9 \mathrm{~F})$ was inserted. The lead was advanced to the RV apex and fix on it (table 3 showed the device implant data and parameters) (Table 3). The lead was fixed to the pulse generator (Figure 8 ). The VF and VT functions were turn on. The anti-bradycardia function was programmed at $40 \mathrm{bpm}$. The pocket was closed. The bill was agreed to be paid over a period of 8 month. He was discharge home on the third day post-procedure.

Follow up: He has been on follow up. He was advice to come for interrogation at 4-week post implant. He was also advice to come to hospital if there any symptom such as chest pain, dizziness or sound from the device. He has been regular with his medications.

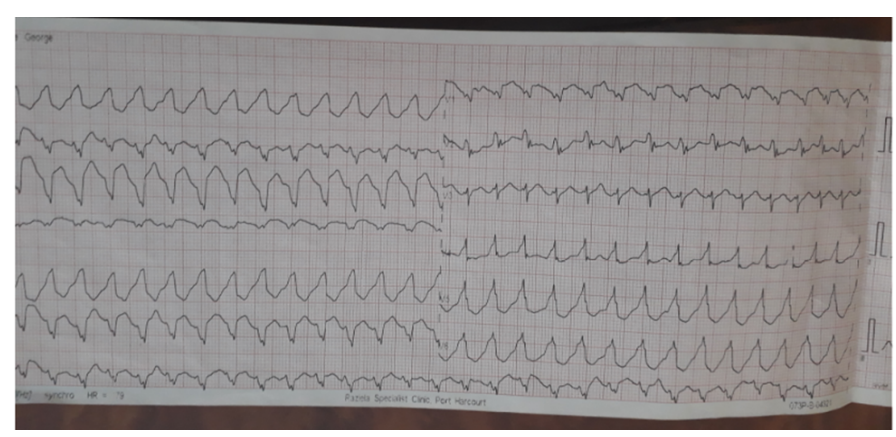

Figure 6. Monomorphic ventricular tachycardia 

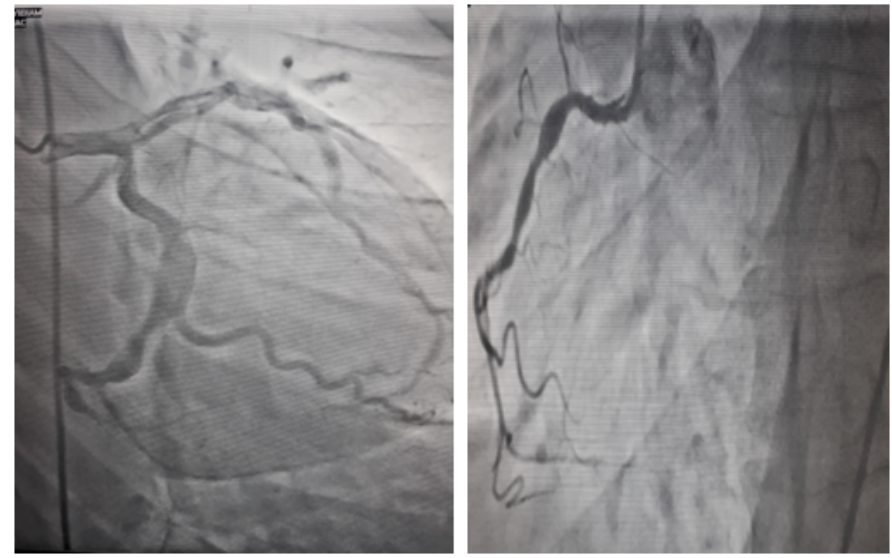

Figure 7. Coronary angiogram showed dilated and aneurismal left anterior decanding artery and right coronary artery
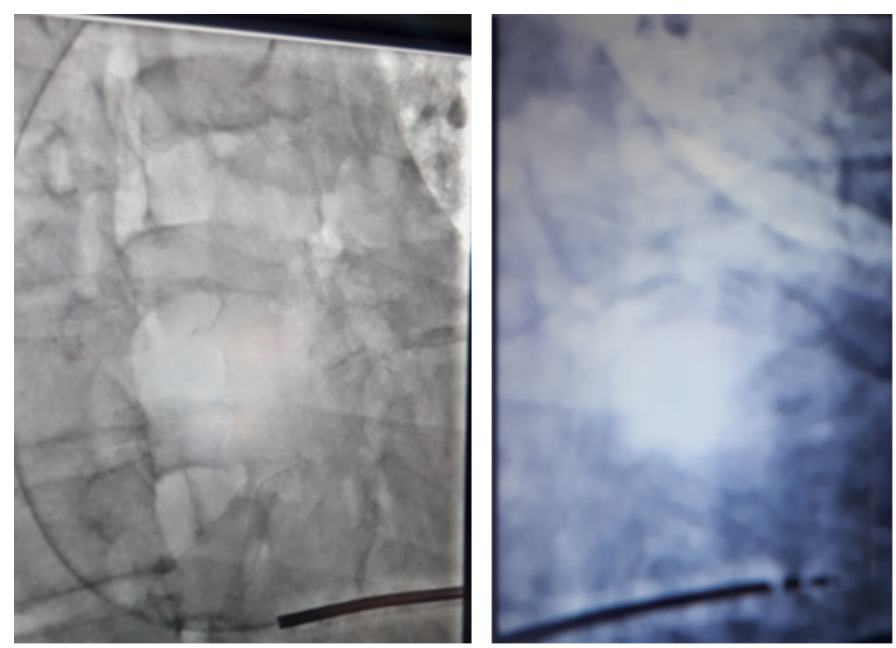

Figure 8. Single chamber implantable cardioverter defibrillator

Table 3. Implant data parameter

\begin{tabular}{|c|c|}
\hline Parameter & RV lead/ generator \\
\hline Manufacturer & Medtronic \\
\hline Name & Protecta \\
\hline RV lead serial number & DTX67046773P \\
\hline RV lead mode & 6783 \\
\hline R wave & 11.6 \\
\hline Impedance & 572 \\
\hline Threshold & 0.4 volts \\
\hline Pulse generator Mode & C434DRX \\
\hline Pulse generator serial number & PKX306451E \\
\hline
\end{tabular}

\section{Discussion}

Ventricular fibrillation (VF) is the commonest cause of sudden cardiac death (SCD). VF is sometimes precipitated by monomorphic or polymorphic ventricular tachycardia (VT). The cardiopulmonary resuscitation (chest compressions and assisted ventilation) can provide transient circulatory support for the patient with cardiac arrest. But the only effective approach for terminating dangerous arrhythmias like VF is electrical defibrillation. Success with external defibrillation led to the development of an implantable defibrillator, followed in 1980 by the first automatic internal defibrillator implantation in humans $[5,6]$. FDA approval followed in 1985, initially only for secondary prevention in survivors of cardiac arrest. ICD could be seen as a pacemaker and a defibrillator because it does the work of pacing in bradycardia patients, anti-tachycardia pacing.

\section{Classification of ICD}

The ICD therapy could be classified according to the chamber that harbor the leads as single and double chamber ICD. Implantable Cardioverter defibrillator could be Transvenous or subcutaneous. Subcutaneous ICD is used for prevention of SCD in patients who have no need for concomitant bradycardia therapy, cardiac resynchronization therapy, or anti-tachycardia pacing therapy. Subcutaneous ICD may also be used in patients with structural heart defects that prevent the wires from going through the veins to the heart.

Wearable Cardioverter defibrillator (WCD) is a device worn by patients who are at risk for sudden cardiac arrest [6,7]. A WCD allows physicians time to assess for their patient's arrhythmic risk and make appropriate plans. The WCD may be prescribed for patients at high risk of SCA following a heart attack, before or after bypass surgery or stent placement, as well as for those with cardiomyopathy or congestive heart failure that places them at particular risk.

Indications for ICD use in clinical practice: The main indications for use of an ICD can be divided into two groups [8-11]. First group is for secondary prevention of sudden cardiac death (SCD) in patients with prior sustained ventricular tachycardia (VT), ventricular fibrillation (VF), or resuscitated SCD thought to be due to VT/VF [9]. Second group is for primary prevention of SCD. The primary prevention include: patients with a prior myocardial infarction (MI) and a left ventricular ejection fraction of $<30 \%$ (MI must have been at least 40 days prior in order to allow time for recovery of LV systolic function) and patients with systolic heart failure (New York Heart Association functional class II or III) and an ejection fraction $<35 \%$ $[9,10]$. Optimal medical therapy must be present and at least 3 months must have elapsed in case the systolic function recovers to an ejection fraction $>35 \%$ in both non-ischemic cardiomyopathy patients and ischemic cardiomyopathy patients who underwent bypass surgery.

ICDs may also be indicated in hypertrophic obstructive cardiomyopathy (HOCM) with any of the following: Syncope, interventricular septal thickness of $\geq 30 \mathrm{~mm}$, documented ventricular tachycardia and/or cardiac arrest, family history of sudden cardiac death, left ventricular systolic dysfunction in the setting of wall thinning $[9,12,13]$.

\section{Clinical benefits of ICD}

An ICD could deliver up to four types of electrical signals to your heart. These include cardiovertion, defibrillation, antitachycardia and bradycardia pacing. Cardioversion gives a strong electrical signal that could be felt like a thump on the chest [14-16]. It resets heart rhythms to normal when it detects a very fast heart rate. Defibrillation sends a very strong electrical signal that restarts the heart [9]. The sensation is painful but lasts only a second. Antitachycardia pacing provides a lowenergy pulse meant to reset a rapid heartbeat. There is no feeling when the pulse occurs. However, one could sense a small flutter in the chest. Bradycardia pacing restores to normal speed a heartbeat that's too slow. In this situation, the ICD works like a pacemaker. Defibrillation can sometimes cause the heart to slow down to a dangerous level. Bradycardia pacing returns the rhythm to normal $[9,17]$.

Complications of ICD therapy: A recent research study reported that the rate of all complications from implantation of transvenous dual chamber ICD was $14.1 \%$ and the rate of major complications 
requiring re-intervention was $6.7 \%[18,19]$. Complication during ICD implantation may include infection at the implant site, allergic reaction to the medications used during the procedure, damage to the vein, pocket hematoma, hemothorax, pneumothorax and inappropriate shock delivery $[20,21]$.

Other complications of implantation include cosmetic issues and psychological problems (a feeling of apprehension about the need for an ICD or fear about getting a shock. For many patients, the psychological issues are not adverse but are beneficial, inasmuch as the high efficacy rate of the device reduces fears of serious rhythm disturbances and the risk of collapse or death and avoids the need to impose limits on their lifestyle. Device-related pain, lead fracture, inappropriate shocks, erosion of device through skin and immunologic rejection are part of chronic complications [22].

ICDs are used in conjunction with an antiarrhythmic drug. The antiarrhythmic medication is used to decrease the frequency of rhythm disturbances and discomfort from shock. Antiarrhythmic medication may also be used to alter the nature of the rhythm disturbance such that it may be less symptomatic and/or more amenable to termination by the low-energy pacing impulses rather than high-energy shocks. In many centers, up to $70 \%$ of patients with an ICD also take $\geq 1$ antiarrhythmic drug. The antiarrhythmic drugs carry with them the cost of the drug, the inconvenience of taking a drug, and the potential for drug-related adverse effects.

Post-procedure follow-up: In the post-procedure follow-up of patient, an ICD is monitored at regular intervals over time (usually every 1-3 months, depending on the specific indications) [23]. The aim of this follow-up is to evaluate what rhythm disturbances have been detected, what electrical treatments have been delivered and whether they worked, and whether the electrical treatments should be modified (i.e., by altering the number and rate of pacing pulses or the energy level of a defibrillation shock) [23]. Monitoring also measures how much of energy is left in the battery, the function of the electrodes, what symptoms the patient has experienced, and whether any other factors that could alter ICD treatments. Monitoring is performed noninvasively, i.e., by applying a programming wand over the chest to allow communication between the ICD and an external computer via electromagnetic waves. When the amount of energy stored in the battery has declined by a predetermined percentage, elective replacement of the ICD is scheduled. This avoids the very rare possibility of having inadequate energy in the battery to power the ICD when an electrical treatment is needed. As long as the electrode wires are functioning well, only the generator needs to be replaced.

Challenges of icd use in sub-saharan africa: The challenges of ICD implantation in the sub-saharan Africa include the following: cost of the device, the people believe system and manpower. Other challenges included lack of interventional cardiologist trained on device implantation and electrophysiologist, lack of access to the equipment needed, late presentation, inadequate education and training of health care providers to test for the condition, low level of public awareness to advocate for receiving testing, lack of funding for device therapy in Nigeria.

\section{Recommendations}

For us in the sub-Saharan Africa to have affordable heart care, the government of the region at various level ranging from local, state and federal government has a lot to do to achieve it. There should be a policy to by government to cut down the cost of various devices used in the management of arrhythmias like bradycardia, ventricular tachycardia and fibrillation. These devices include pacemaker, ICD, and cardiac resynchronization therapy. The government could invite the device manufacturing companies to a round table meeting to work out a way to reduce cost for the sub-Sahara Africa region. Government should create soft landing for the device companies. This include waver of import duties and country registration of the device. This will make their product cheap accessible and affordable. Training of human resources locally and abroad for the use of these devices could be done by government, non-governmental organization and the device companies. Government and device companies in conjunction with the private sector should fund research in the region into development of affordable devices for the population. Regional government should set up a regulatory body to ensure implement and adherence of the policy for the growth of the cardiovascular health of the sub-Sahara Africa.

\section{Conclusion}

This case series highlighted the challenges that are being faced by device implanting cardiologist in Nigeria. Suggested recommendations to overcome these challenges are also noted.

\section{Declaration of patient consent}

The authors certify that they have obtained all appropriate patient consent forms. In the form the patient(s) has/have given his/her/their consent for his/her/their images and other clinical information to be reported in the journal. The patients understand that their names and initials will not be published, and due efforts will be made to conceal their identity, but anonymity cannot be guaranteed.

\section{Financial support and sponsorship}

$$
\text { Nil. }
$$

\section{Conflicts of interest}

There are no conflicts of interest.

\section{References}

1. Wever EF, Hauer RN, van Capelle FL, Tijssen JG, Crijns HJ, et al. (1995) Randomized study of implantable defibrillator as first-choice therapy versus conventional strategy in postinfarct sudden death survivors. Circulation 91: 2195-2203. [Crossref]

2. Naksuk N, DeSimone CV, Kapa S, Asirvatham SJ (2014) Prevention of sudden cardiac death beyond the ICD: have we reached the boundary or are we just burning the surface?. Indian Heart $J$ 1: 120-128. [Crossref]

3. Lopera G, Curtis AB (2009) Risk stratification for sudden cardiac death: curren approaches and predictive value. Curr Cardiol Rev 5: 56-64. [Crossref]

4. Yousuf O, Chrispin J, Tomaselli GF, Berger RD (2015) Clinical Management and Prevention of Sudden Cardiac Death. Circ Res 116: 2020-2040. [Crossref]

5. Mirowski M, Mower MM, Staewen WS, Tabatznik B, Mendeloff AI (1970) Standby automatic defibrillator. An approach to prevention of sudden coronary death. Arch Intern Med 126: 158-161. [Crossref]

6. Mirowski M, Reid PR, Mower MM, Watkins L, Gott VL, et al. (1980) Termination of malignant ventricular arrhythmias with an implanted automatic defibrillator in human beings. N Engl J Med 303: 322-334. [Crossref]

7. Barraud J, Cautela J, Orabona M, Pinto J, Missenard O, et al. (2017) Wearable cardioverter defibrillator: Bridge or alternative to implantation?. World J Cardiol 9: 531-538. [Crossref]

8. Russo AM, Stainback RF, Bailey SR, Epstein AE, Heidenreich PA, et al. (2013) ACCF/HRS/AHA/ASE/HFSA/SCAI/SCCT/SCMR 2013 appropriate use criteria for implantable cardioverter-defibrillators and cardiac resynchronization therapy: a report of the American College of Cardiology Foundation appropriate use criteria task force, Heart Rhythm Society, American Heart Association, American Society of Echocardiography, Heart Failure Society of America, Society for Cardiovascula Angiography and Interventions, Society of Cardiovascular Computed Tomography, and Society for Cardiovascular Magnetic Resonance. J Am Coll Cardiol 61: 1318-1387. [Crossref] 
9. Al-Khatib SM, Stevenson WG, Ackerman MJ, Bryant WJ, Callans DJ, et al. (2018) 2017 AHA/ACC/HRS Guideline for Management of Patients With Ventricular Arrhythmias and the Prevention of Sudden Cardiac Death: A Report of the American College of Cardiology/American Heart Association Task Force on Clinical Practice Guidelines and the Heart Rhythm Society. J Am Coll Cardiol 72: 91-99. [Crossref]

10. Anvari A, Stix G, Grabenwöger M, Schneider B, Türel Z, et al. (1996) Comparison of three cardioverter defibrillator implantation techniques: initial results with transvenous pectoral implantation. Pacing Clin Electrophysiol 19: 1061-1071. [Crossref]

11. Wilkoff BL, Fauchier L, Stiles MK, Morillo CA, Al-Khatib SM, et al. (2016) 2015 HRS/EHRA/APHRS/SOLAECE expert consensus statement on optimal implantable cardioverter-defibrillator programming and testing. Europace 18: 159-183. [Crossref]

12. Flaker GC, Tummala R, Wilson J (1998) Comparison of right- and left-sided pectoral implantation parameters with the Jewel active can cardiodefibrillator. The World Wide Jewel Investigators. Pacing Clin Electrophysiol 21: 447-478. [Crossref]

13. Day JD, Doshi RN, Belott P, Birgersdotter-Green U, Behboodikhah M, et al. (2007) Inductionless or limited shock testing is possible in most patients with implantable cardioverter- defibrillators/cardiac resynchronization therapy defibrillators: results of the multicenter ASSURE Study (Arrhythmia Single Shock Defibrillation Threshold Testing Versus Upper Limit of Vulnerability: Risk Reduction Evaluation With Implantable Cardioverter-Defibrillator Implantations). Circulation 115: 2382-2396. [Crossref]

14. DiMarco JP (2003) Implantable cardioverter-defibrillators. N Engl J Med 349: 18361847.

15. Thijssen J, Borleffs CJ, van Rees JB, Man S, de Bie MK, et al. (2012) Implantable cardioverter-defibrillator longevity under clinical circumstances: an analysis according to device type, generation, and manufacturer. Heart Rhythm 9: 513-519. [Crossref]
16. Israel CW, Grönefeld G, Iscolo N, Stöppler C, Hohnloser SH (2001) Discrimination between ventricular and supraventricular tachycardia by dual chamber cardioverter defibrillators: importance of the atrial sensing function. Pacing Clin Electrophysiol 24: 183-195. [Crossref]

17. Mattke S, Markewitz A, Müller D, Grünewald A, Fiek M, et al. (1997) The combined transvenous implantation of cardioverter defibrillators and permanent pacemakers. Pacing Clin Electrophysiol 20: 2775-2789. [Crossref]

18. Theuns DAMJ, Crozier IG, Barr CS, Hood MA, Cappato R, et al. (2015) Longevity of the subcutaneous implantable defibrillator: long-term follow-up of the European Regulatory Trial Cohort. Circ Arrhythm Electrophysiol 8: 1159-1163. [Crossref]

19. Zanon F, Martignani C, Ammendola E, Menardi E, Narducci ML, et al. (2016) Device Longevity in a Contemporary Cohort of ICD/CRT-D Patients Undergoing Device Replacement. J Cardiovasc Electrophysiol 27: 840-868. [Crossref]

20. Freeman JV, Wang Y, Curtis JP, Heidenreich PA, Hlatky MA(2012) Physician procedure volume and complications of cardioverter-defibrillator implantation. Circulation 125: 57-64. [Crossref]

21. Curtis JP, Luebbert JJ, Wang Y, Rathore SS, Chen J, et al. (2009) Association of physician certification and outcomes among patients receiving an implantable cardioverter-defibrillator. JAMA 301: 1661-1670. [Crossref]

22. Daubert JP, Zareba W, Cannom DS, McNitt S, Rosero SZ, et al. (2008) Inappropriate implantable cardioverter-defibrillator shocks in MADIT II: frequency, mechanisms, predictors, and survival impact. J Am Coll Cardiol 51: 1357-1365. [Crossref]

23. Burri H, Senouf D (2009) Remote monitoring and follow-up of pacemakers and implantable cardioverter defibrillators. Europace 11: 701-709. [Crossref]

24. Health Quality Ontario (2018) Remote Monitoring of Implantable CardioverterDefibrillators, Cardiac Resynchronization Therapy and Permanent Pacemakers: A Health Technology Assessment. Ont Health Technol Assess Ser 18: 1-199. [Crossref]

Copyright: $(2020$ Auchi EE. This is an open-access article distributed under the terms of the Creative Commons Attribution License, which permits unrestricted use, distribution, and reproduction in any medium, provided the original author and source are credited. 